Review

\title{
Phospholipids and Alzheimer's Disease: Alterations, Mechanisms and Potential Biomarkers
}

\section{Marko Kosicek and Silva Hecimovic *}

Division of Molecular Medicine, Rudjer Boskovic Institute, Bijenicka 54, 10000 Zagreb, Croatia;

E-Mail: marko.kosicek@irb.hr

* Author to whom correspondence should be addressed; E-Mail: silva.hecimovic@irb.hr;

Tel./Fax: +385-1-4571-284.

Received: 27 November 2012; in revised form: 20 December 2012 / Accepted: 24 December 2012 /

Published: 10 January 2013

\begin{abstract}
Brain is one of the richest organs in lipid content. Phospholipids (glycerophospholipids and sphingolipids) are important building blocks of cell membranes, which provide an optimal environment for protein interactions, trafficking and function. Because of that, alterations in their cellular levels could lead to different pathogenic processes in the brain, such as in Alzheimer's disease (AD), the most common type of dementia among older populations. There is increasing evidence that phospholipid changes occur during pathogenic processes in AD. It is known that lipids are tightly connected with metabolism of the Amyloid Precursor Protein (APP), which produces Amyloid-beta peptide $(A \beta)$, the main component of senile plaques, which represent the main pathological hallmark of AD. However, the mechanism(s) of the lipid-effect on A $\beta$ metabolism and AD pathogenesis is still not completely understood. This review summarizes the current knowledge on phospholipid changes occurring during normal aging and discusses phospholipid changes in the human brain associated with different stages of $\mathrm{AD}$, as well changes in the cerebrospinal fluid and blood/plasma, which are interesting potential biomarkers for $\mathrm{AD}$ diagnosis and disease monitoring. At the end, we have discussed future perspectives of phospholipid changes as potential biomarkers and as targets for development of novel treatment strategies against $\mathrm{AD}$.
\end{abstract}

Keywords: phospholipid; Alzheimer's disease; biomarker 
Abbreviations: A $\beta$, Amyloid beta peptide; AD, Alzheimer's disease; Apo E, apolipoprotein E; APP, Amyloid Precursor Protein; CDR, clinical dementia rating; CSF, cerebrospinal fluid; CTF, Amyloid Precursor Protein $C$-terminal fragments; ESI-MS, electrospray mass spectrometry; GC, gas chromatography; HPG, subiculum of the hippocampus and parahippocampal gyrus; HPLC, high-performance liquid chromatography; IPL, inferior parietal lobe; MFG, middle frontal gyrus; MTG, middle temporal gyrus; PC, phosphatidylcholine; PE, phosphatidylethanolamine; PI, phosphatidylinositol; PPE, ethanolamine plasmalogen; sAPP, soluble Amyloid Precursor Protein $N$-terminal fragments $\alpha$ or $\beta$; SM, sphingomyelin; SMFG, superior-middle frontal gyrus; SMTG, superior-middle temporal gyrus; SFG, superior frontal gyrus; STG, superior temporal gyrus; TLC, thin layer chromatography.

\section{Introduction}

Phospholipids are structurally and biologically important molecules, which form cellular membranes and are involved in the behavior of membrane proteins, receptors, enzymes and ion channels intracellularly or at the cell surface. Since the brain is one of the richest organs in lipid content, changes in the brain phospholipid levels could lead to different pathogenic processes. Different regions of the brain differ in phospholipid composition. Development of new and sensitive techniques, such as mass spectrometry imaging, enabled more precise determination of regional phospholipid distribution and provided a powerful tool for clarifying the role of phospholipids in the brain [1]. To differentiate between pathogenic and normal aging process, it is imperative to elucidate what changes in brain phospholipid levels occur during aging. Concentrations of most lipids in the human brain decrease after the age of 50. Phosphatidylinositol (PI), phosphatidylethanolamine (PE) and phosphatidylcholine (PC) brain levels decrease very slowly with age, with less than $10 \%$ loss in the period between age 40 and age 100 [2]. In another study, 10\%-20\% loss of phospholipids in different brain regions was observed only in individuals between age 89 and 92 compared to 33- to 36- year-old individuals, while phospholipid composition in various brain regions stayed unchanged during aging [3]. Phospholipid reduction starts slowly after age 20 and, after age 80, becomes more pronounced, with no significant difference in lipid profile between male and female brains [4,5]. In contrast, ethanolamine plasmalogen (PPE) brain levels decrease 18\% (till the age of 70) and 29\% (till the age of 100), and sphingomyelin brain levels decrease $12 \%$ and $20 \%$ in the same time period, respectively [6]. Changes in other lipid classes during aging and the role of lipids in the aging brain were recently extensively reviewed [7].

\section{Phospholipid Changes in Alzheimer's Disease}

\subsection{Alzheimer's Disease}

Alzheimer's disease (AD) is the most common neurodegenerative disorder among older populations. The major risk factor for $\mathrm{AD}$ is age, although the exact cause of the disease and pathogenic mechanism of degenerative processes in the brain are still not known. AD is usually developed after age of 65 with the incidence of 67 cases per 1000 in populations older than 65 . The risk of disease doubles with every five years of age, with higher rates of incidence for women 
(men to women rate ratio around 0.5) [8]. Systematic review of epidemiological studies in 2005 estimated the number of AD patients worldwide at 24 million people. Projection says that the number of affected individuals will double every 20 years to 42 million by 2020 and 81 million by 2040. Sixty percent of patients live in developing countries, and the number will rise to $71 \%$ by 2040 [9].

The neuropathological characteristics of Alzheimer's disease are amyloid plaques (aggregates of amyloid- $\beta$ peptides) and neurofibrillary tangles (formed by accumulation of hyperphosphorylated tau protein), which firstly affect the medial temporal and parietal lobe and part of the frontal cortex of the brain [10]. Amyloid- $\beta(\mathrm{A} \beta)$ peptide is produced by proteolytic processing of the Amyloid Precursor Protein (APP). In the first step, APP is cleaved by either $\alpha$ - or $\beta$-secretase producing soluble sAPP $\alpha$ or sAPP $\beta$ fragments and membrane-bound $C$-terminal fragments, $\mathrm{CTF} \alpha$ or $\mathrm{CTF} \beta$, respectively. Both CTFs could be further cleaved by $\gamma$-secretase liberating p3 peptide (if the substrate is CTF $\alpha$ ) or A $\beta$ (if the substrate is CTF $\beta$ ) [11]. The availability of APP to $\alpha$-secretase (non-amyloidogenic pathway) or $\beta$-secretase (amyloidogenic pathway) determines how much of the pathogenic A $\beta$ peptide will be produced. Since these two secretases/pathways are likely to be spatially separated within the cell, it is possible that alterations of APP trafficking, caused by lipid changes, may be the primary cause of the disease process.

Certain diagnosis of AD can be made only post-mortem. However, today in specialized clinics, using a combination of tools, AD can be diagnosed with more than 95\% accuracy. These tools include taking a disease history from patients and their families and assessing cognitive function by neuropsychological tests - the criteria of the National Institute of Neurological and Communicative Diseases and Stroke and the Alzheimer's disease and Related Disorders Association (NINCDS-ADRDA) - in combination with neuroimaging (CT, MRI and PET) to exclude other causes of dementia [12]. In addition, measurement of cerebrospinal fluid (CSF) levels of A $\beta 42$, tau and phosphorylated tau can help in differential diagnosis of $\mathrm{AD}$ and can be useful for predicting $\mathrm{AD}$ in individuals with mild cognitive impairment (MCI) [13].

\subsection{Phospholipid Changes in the Brain of Individuals with Alzheimer's Disease}

The overview of the published work on phospholipid brain levels in AD is shown in Table 1 . Publications from late 1980 and 1990 suggested that decreased brain phospholipid levels and alterations in brain phospholipid metabolism could be connected with AD. Decreased PI levels [14,15] and PE levels [14,16,17], especially decrease of PPE relative to PE [18,19], were found in post-mortem brain samples from individuals with AD compared to controls. In parallel, a decreased of PC [16,19] or unchanged PC levels [14,17] have been reported. In addition, 73\% reduction in choline plasmalogen was observed in frontal cortex from individuals with AD compared to controls [20]. All these studies used traditional analytical techniques for phospholipid profiling, which require larger brain samples that could potentially lead to cross contamination between different brain regions and gray and white matter. Another analytical approach, ${ }^{31} \mathrm{P}$ NMR phospholipid profiling, supported those findings and revealed a mild reduction in PI, PE and PC levels in the combined brain regions' lipid extracts from individuals with AD compared to non-demented controls [21]. Development of mass spectrometry provided a great tool for lipidomics, enabling simultaneous analysis of more phospholipid classes using a small sample size. Han and coworkers developed an electrospray ionization mass spectrometry 
(ESI-MS) platform for sensitive phospholipid profiling and showed different changes of PPE levels during AD development between gray and white matter. Deficiency of PPE in the white matter was already around $40 \%$ in an early stage of $\mathrm{AD}$ and was constant during disease progression, while deficiency of PPE in the gray matter was gradually increased from $10 \%$ to $30 \%$ during disease progression [22]. Interestingly, in an early stage of $\mathrm{AD}$, brain levels of other phospholipid classes (PC, PI and PE) in both white and gray matter were unchanged [23].

Beside glycerophospholipid changes, alterations in the brain sphingophospholipid levels also occur during AD. Post-mortem brain analysis gave contradictory results about sphingomyelin (SM) levels in AD brain, depending on the brain tissue analyzed (e.g., whole brain extract or specific brain region; separation or no separation of white and gray matter) and on the used analytical approach. Decreased SM levels were observed in soluble fractions, but unchanged in membrane fractions from AD brains compared to control brains using enzymatic assay [24]. Significantly decreased levels of SM were reported in the middle frontal gyrus of $\mathrm{AD}$ patients compared with controls, but were not decreased in the cerebellum [25]. In contrast, Bandaru and coworkers found significant increase of SM in middle frontal gyrus gray matter, while in middle frontal gyrus white matter, there were no differences in SM levels using ESI-MS [26]. ${ }^{31} \mathrm{P}$ NMR approach found an increase in SM levels in combined brain regions from $\mathrm{AD}$ compared to controls, but not in all brain regions. Interestingly, there was statistically significant increase of SM in the cerebellum, but not in the superior/middle frontal gyrus, which showed a slight, but not statistically significant, increase in SM levels [21]. In an early stage of AD, SM levels in gray and white matter were unchanged in both frontal cortex and cerebellum [23]. Even though the results on SM levels in AD brains are confusing, there is a strong evidence that ceramide, the main precursor in sphingolipid metabolism, is increased in AD brains [23-25]. The most affected sphingolipid in AD brain is sulfatide, which is depleted up to $93 \%$ in gray matter and up to $58 \%$ in white matter [23]. Sphingolipid metabolism changes in AD have been thoroughly reviewed elsewhere [27-29]. To explore whether these phospholipid changes could be used for AD diagnosis or for monitoring the disease progression/treatment, it is important to determine if their changes could be observed in a sample more appropriate for diagnostic purposes, such as CSF or blood.

Table 1. Phospholipid changes in the brain of individuals with Alzheimer's disease.

\begin{tabular}{|c|c|c|c|}
\hline $\begin{array}{l}\text { Lipid } \\
\text { class }\end{array}$ & $\begin{array}{c}\text { Change/ } \\
\text { Normalization }\end{array}$ & Sample size/Examined brain regions/Analytical method & Reference \\
\hline PI & decreased/wet weight & $9 \mathrm{AD}$ and 9 controls/HPG, SMTG, IPL and cerebellum/TLC & [14] \\
\hline PI & decreased/wet weight & $17 \mathrm{AD}$ and 18 controls/anterior temporal cortex/TLC & {$[15]$} \\
\hline PI & decreased/relative & $\begin{array}{c}45 \mathrm{AD} \text { and } 11 \text { controls/SMFG, STG, IPL, occipital cortex } \\
\text { and cerebellum/ } /{ }^{13} \mathrm{P} \text { NMR }\end{array}$ & [21] \\
\hline $\mathrm{PE}$ & decreased/wet weight & $9 \mathrm{AD}$ and 9 controls/HPG, SMTG, IPL and cerebellum/TLC & {$[14]$} \\
\hline PE & decreased/DNA & $\begin{array}{l}10 \mathrm{AD} \text { and } 10 \text { controls/frontal, primary auditory and parietal } \\
\text { cortex/photometrical phosphorus determination }\end{array}$ & {$[16]$} \\
\hline PPE & decreased/relative & $9 \mathrm{AD}$ and 9 controls/middle-temporal cortex/HPLC and TLC & {$[18]$} \\
\hline PPE & decreased/phosphate & $\begin{array}{c}15 \mathrm{AD} \text { and } 13 \text { controls/frontal cortex, hippocampus and } \\
\text { white matter/HPLC and GC }\end{array}$ & {$[19]$} \\
\hline PPE & decreased/relative & $\begin{array}{l}45 \mathrm{AD} \text { and } 11 \text { controls/SMFG, STG, IPL, occipital cortex } \\
\text { and cerebellum } /{ }^{13} \mathrm{P} \text { NMR }\end{array}$ & [21] \\
\hline
\end{tabular}


Table 1. Cont.

\begin{tabular}{|c|c|c|c|}
\hline $\begin{array}{l}\text { Lipid } \\
\text { class }\end{array}$ & $\begin{array}{c}\text { Change/ } \\
\text { Normalization }\end{array}$ & Sample size/Examined brain regions/Analytical method & Reference \\
\hline PPE & decreased/protein & $\begin{array}{c}6 \mathrm{CDR}=0 ; 6 \mathrm{CDR}=0.5 ; 6 \mathrm{CDR}=1 ; 6 \mathrm{CDR}=2 ; \\
6 \mathrm{CDR}=5 / \text { white and gray matter from } \mathrm{SFG}, \mathrm{STG}, \mathrm{IPL} \text { and } \\
\text { cerebellum/ESI-MS }\end{array}$ & [22] \\
\hline $\mathrm{PC}$ & $\begin{array}{l}\text { unchanged/wet } \\
\text { weight }\end{array}$ & $9 \mathrm{AD}$ and 9 controls/HPG, SMTG, IPL and cerebellum/TLC & {$[14]$} \\
\hline $\mathrm{PC}$ & decreased/DNA & $\begin{array}{c}10 \mathrm{AD} \text { and } 10 \text { controls/frontal, primary auditory and parietal } \\
\text { cortex/HPLC-fluorimetric detection }\end{array}$ & {$[16]$} \\
\hline PC & $\begin{array}{l}\text { unchanged/wet } \\
\text { weight }\end{array}$ & $\begin{array}{c}6 \mathrm{AD} \text { and } 4 \text { controls/gray matter from frontal cortex, parietal } \\
\text { and temporal region/HPLC }\end{array}$ & {$[17]$} \\
\hline $\mathrm{PC}$ & decreased/phosphate & $\begin{array}{c}15 \mathrm{AD} \text { and } 13 \text { controls/frontal cortex, hippocampus and } \\
\text { white matter/HPLC and GC }\end{array}$ & [19] \\
\hline SM & decreased/protein & $\begin{array}{l}9 \mathrm{AD} \text { and } 6 \text { controls/gray matter from frontotemporal } \\
\text { area/enzymatic assay-HPLC }\end{array}$ & {$[24]$} \\
\hline SM & decreased/relative & $7 \mathrm{AD}$ and 7 controls/MFG, SFG and cerebellum/ESI-MS & {$[25]$} \\
\hline SM & increased/relative & $30 \mathrm{AD}$ and 26 controls/MFG, MTG and cerebellum/ESI-MS & [26] \\
\hline SM & increased/relative & $\begin{array}{c}45 \mathrm{AD} \text { and } 11 \text { controls/SMFG, STG, IPL, occipital cortex } \\
\text { and cerebellum/ }{ }^{31} \mathrm{P} \text { NMR }\end{array}$ & [21] \\
\hline ceramide & increased/protein & $\begin{array}{c}6 \mathrm{CDR}=0 ; 6 \mathrm{CDR}=0.5 ; 6 \mathrm{CDR}=1 ; 6 \mathrm{CDR}=2 ; \\
6 \mathrm{CDR}=5 / \text { white and gray matter from MFG, STG, IPL and } \\
\text { cerebellum/ESI-MS }\end{array}$ & {$[22]$} \\
\hline ceramide & increased/protein & $\begin{array}{c}9 \mathrm{AD} \text { and } 6 \text { controls/gray matter from frontotemporal } \\
\text { area/enzymatic assay-HPLC }\end{array}$ & [24] \\
\hline ceramide & increased/relative & $\begin{array}{c}7 \mathrm{AD} \text { and } 7 \text { controls } / \mathrm{MFG}, \mathrm{SFG} \text { and cerebellum/ESI-MS } \\
6 \mathrm{CDR}=0 ; 6 \mathrm{CDR}=0.5 ; 6 \mathrm{CDR}=1 ; 6 \mathrm{CDR}=2 ;\end{array}$ & {$[25]$} \\
\hline sulfatide & decreased/protein & $\begin{array}{c}6 \mathrm{CDR}=5 / \text { white and gray matter from MFG, STG, IPL and } \\
\text { cerebellum/ESI-MS }\end{array}$ & [23] \\
\hline
\end{tabular}

\subsection{Phospholipid Changes in the CSF and Blood of Individuals with Alzheimer's Disease}

CSF is the most informative fluid source for neurodegenerative disease diagnosis/research, because of its constant physical contact with brain. Despite the fact that many phospholipid alterations in the $\mathrm{AD}$ brain have been reported, only a few studies attempted to monitor those changes in the CSF (Table 2). Unchanged PC levels, but decreased lysoPC/PC ratio, have been reported in the CSF from individuals with $\mathrm{AD}$ compared to individuals with memory complaints, but without dementia [30], together with elevation in different PC metabolites, suggesting that $\mathrm{AD}$ is accompanied with increased PC hydrolysis [31]. Sphingolipid alterations found in AD brain were also observed in the CSF. Increased levels of ceramides have been found in the CSF from individuals with AD compared to age-matched individuals with amyotrophic lateral sclerosis (ALS) and other neurological controls [32]. Han and coworkers found approximately $40 \%$ reduction of sulfatides in the CSF in an early stage of $\mathrm{AD}$ and unchanged levels of PI. The authors suggested that CSF sulfatide/PI ratio could be a sensitive and specific biomarker for early AD diagnosis [33]. Recently, we developed a high-throughput-amenable and sensitive HPLC-ESI/MS method for CSF phospholipid screening [34] 
and examined phospholipid levels in the CSF from AD patients representing different stages of the disease, including prodromal AD. We observed a statistically significant increase (around 50\%) in SM levels between prodromal AD group and cognitively normal group, while PI, PE and PC levels were unchanged in all examined groups [35].

Although CSF is the most informative sample for monitoring brain pathological processes, blood/plasma is much easier and less invasive to collect and, thus, is more suitable for routine diagnosis and/or disease monitoring. Due to blood-brain barrier and huge influence of diet and other body processes outside the brain on blood lipid levels, it is difficult to make a direct link between blood phospholipid levels and neurodegenerative processes. However, Mielke and coworkers reported a connection between lower levels of SM and ceramides and memory impairment [36]. In addition, they found significantly lower ceramide levels in plasma from individuals with mild cognitive impairment, while no difference was observed in plasma ceramide levels between AD and non-demented controls [37]. Potential usage of peripheral sphingolipid as biomarkers of AD was recently reviewed elsewhere [38].

Table 2. Phospholipid changes in the cerebrospinal fluid (CSF) of individuals with Alzheimer's disease.

\begin{tabular}{cccc}
\hline Lipid class & Change & Sample size/Sample collection & Reference \\
\hline PC & decreased lysoPC/PC & $30 \mathrm{AD}$ and 31 controls/post mortem & {$[30]$} \\
PC & increased PC metabolites & $12 \mathrm{AD}$ and 30 controls/lumbar puncture & {$[31]$} \\
SM & increase in prodromal AD & $21 \mathrm{AD}$ and 16 controls/lumbar puncture & {$[35]$} \\
ceramide & increase & $16 \mathrm{AD}$ and 14 controls/lumbar puncture & {$[32]$} \\
sulfatide & decrease & $19 \mathrm{CDR}=0 ; 20 \mathrm{CDR}=0.5 /$ lumbar puncture & {$[33]$} \\
\hline
\end{tabular}

\section{Lipids as Biomarkers for Alzheimer's Disease Diagnosis and as Targets for Potential Novel Treatment Strategies}

As we pointed out earlier, currently, the diagnosis of $\mathrm{AD}$ is based on the combination of different tests/methods for the exclusion of other causes of dementia. Neurological tests, which are still the gold standard for the diagnosis of $\mathrm{AD}$, are mostly accurate in identifying individuals with already developed dementia. The biggest challenge for clinicians and for application of novel therapies against AD is to accurately recognize prodromal $\mathrm{AD}$ patients and/or individuals with mild cognitive impairment (MCI) who will develop AD. Studies suggest that CSF biomarkers p-tau, total tau and A $\beta 42$ are useful for $\mathrm{AD}$ diagnosis and for identifying individuals with prodromal AD in MCI cases [13]. The multicenter study found that these CSF biomarkers identify incipient AD with good accuracy, but with less accuracy compared to single-center studies. Additional effort is needed for standardization of analytical techniques and clinical procedures to avoid variability between different centers [39]. Although so far reported CSF/blood phospholipid changes are not specific and sensitive enough to be a diagnostic biomarker, phospholipid alterations could lead to membrane instability and synaptic loss and, in that way, contribute to AD pathology $[18,20]$. However, sphingolipid alterations are promising candidates as AD biomarkers. 


\subsection{Sulfatides}

The most promising sphingolipid candidate for early AD diagnosis is reduction of CSF sulfatide levels [33]. Sulfatide brain levels were not reduced in dementia with Lewy bodies and were elevated in different brain regions of individuals with Parkinson's disease [40]. CSF sulfatide levels in individuals with vascular dementia were elevated compared to controls and individuals with AD [41], and low CSF sulfatide levels could predict progression of white matter lesions [42]. However, specificity and sensitivity of sulfatide as a potential biomarker of AD has yet to be determined.

Mechanistic studies suggest that apolipoprotein E (apoE) plays an important role in the regulation of sulfatide levels in the brain [43]. ApoE is a primer apolipoprotein in the brain, which mediates the transport of cholesterol, triacylglycerides, phospholipids and sulfatides in the brain. In humans, ApoE is present in three isoforms. The most common isoform is apoE3 (with Cys 112 and Arg 158), following by apoE2 (with Cys 112 and Cys 158) and apoE4 (with Arg 112 and Arg 158). So far, apoE4 has been proven to be a genetic risk factor for AD [44]. ApoE can modulate A $\beta$ metabolism and accumulation in apoE isoform-dependent manner- $\mathrm{A} \beta$ accumulation rises in the order apoE2, apoE3 and apoE4. Although the mechanism is not completely understood, it seems that apoE can bind $\mathrm{A} \beta$ and prevent formation of toxic $A \beta$ oligomers and fibrils [45]. Furthermore, neurotoxic microglial activation also depends on apoE phenotype and rises in the order apoE2, apoE3 and apoE4, suggesting that apoE can modulate $\mathrm{AD}$ by multiple apoE isoform-specific mechanisms [46]. ApoE regulates brain sulfatide levels by transporting sulfatide from cells to the CSF or by endocytic recycling of sulfatide-containing apoE particles. In addition, cognitively normal individuals with one or two apoE4 alleles have more sulfatides in the CSF compared to apoE3 homozygous, suggesting that apoE may be involved in the sulfatide loss in AD [47]. The exact connection between sulfatide deficiency and AD is still not clear, but CSF sulfatide levels alone or in combination with other biomarkers could contribute to early AD diagnosis and/or monitoring of therapeutic treatments [48].

\subsection{Ceramide}

Ceramide is the major precursor in sphingolipid metabolism and a powerful second messenger that regulates growth inhibition, apoptosis and stress response. Together with other bioactive sphingolipids, it is important for neuronal signaling and function [49,50]. Elevation of ceramide levels in AD reaches the highest point in MCI cases. That is probably the result of sulfatide degradation, which occurs in an early stage of $\mathrm{AD}$ since the molecular species profile of ceramides is similar to the molecular species profile of sulfatides in individuals with MCI [23]. The study, which examined changes in the expression of genes coding ceramide metabolism enzymes, found both upregulation of genes involved in de novo synthesis of ceramide and downregulation of genes involved in glycosphingolipid synthesis. Those changes were visible in an early stage of $\mathrm{AD}$, confirming that observed changes of sulfatide and ceramide levels in $\mathrm{AD}$ brain are connected with disturbed sphingolipid metabolism [51]. In vitro studies suggest that $A \beta$ activates sphingomyelin hydrolysis and causes ceramide accumulation $[25,52]$. Sphingomyelin can be hydrolyzed by acid, alkaline or neutral sphingomyelinases named after the $\mathrm{pH}$ at which they are the most active. In $\mathrm{AD}$, brain increased acid sphingomyelinase activity has been reported [24], while in vitro and animal studies suggest involvement of both acid and neutral 
sphingomyelinases in ceramide accumulation due to $A \beta$ stimulation. Ceramide can also influence $A \beta$ production by stabilizing $\beta$-secretase (BACE1) and promoting amyloidogenic processing of APP [53,54]. Although there is no clear mechanism, which could explain the ceramide role in A $\beta$ cytotoxicity, several mechanisms have been proposed [55]. Because of its connection with pathobiological processes and changes in CSF and plasma levels in an early stage of $\mathrm{AD}$, ceramide could potentially be a candidate as an AD biomarker.

\subsection{Lipid Rafts}

Since all enzymes involved in APP processing ( $\alpha$-, $\beta$ - and $\gamma$-secretase) are transmembrane proteins, as well as APP and its $C$-terminal fragments ( $\alpha \mathrm{CTF}$ and $\beta \mathrm{CTF})$, it is logical to assume that lipid within the membrane bilayer may play an important role in APP processing and A $\beta$ production. Lipid changes in $\mathrm{AD}$ (especially in cholesterol and sphingolipid metabolism) suggest that lipid rafts could be involved in AD pathogenesis. By definition lipid rafts are 10-200 nm small, heterogeneous, highly dynamic membrane domains enriched in sterol and sphingolipids [56]. Lipid rafts have many alternative names, mostly based on the method of their isolation (e.g., detergent resistant membranes DRM). There are different methods for lipid raft isolation and different theoretical models about their structure and formation [57]. Numerous studies suggested that amyloidogenic processing of APP occurs in lipid rafts, since APP, $\beta$-secretase (BACE1) and $\gamma$-secretase are localized in lipid rafts [58-61]. In addition, we reported that increased levels of cholesterol and sphingolipids in the Niemann-Pick type C (NPC) disease cellular model lead to increased localization of APP in lipid rafts, which supports the link between NPC disease and AD [62]. Under normal conditions, only a small portion of BACE1 is localized in lipid rafts. Targeting of BACE1 to lipid rafts by adding an glycosylphosphatidylinositol (GPI) anchor at the place of transmembrane and $C$-terminal domain increased the production of sAPP $\beta$ and A $\beta$ [63]. In contrast, $\alpha$-secretase (ADAM10) is under normal conditions exclusively present in non-raft fractions. Replacing the transmembrane and cytosolic domain of ADAM10 with GPI anchor caused retargeting of ADAM10 to lipid rafts and reduced amyloidogenic APP processing [63]. Overall, these results imply that regulation of lipid rafts protein targeting could be a good approach for controlling APP amyloidogenic processing. However, another signal for BACE1 targeting to lipid rafts is S-palmitoylation of Cys 474, 478, 482 and 485. Mutations of these Cys residues to Ala relocated BACE1 out of lipid rafts, but without affecting APP amyloidogenic processing [64]. The same approach revealed that $S$-palmitoylation of $\gamma$-secretase complex subunits nicastrin and APH1 is important for their stability and raft localization, but not for $\gamma$-secretase processing of APP [65]. Another interesting approach was the synthesis of the membrane-anchored version of BACE1 inhibitor, which was targeted to endosomes and lipid rafts, where its local concentration was increased. In that way, this inhibitor was more potent and focused on active BACE1 [66]. Although the role of lipids rafts in AD pathogenesis is still controversial (as lipid rafts are controversial per se), it is evident that specific membrane platforms are involved in APP, BACE1 and $\gamma$-secretase colocalization, APP processing and formation of the pathogenic A $\beta$ peptide. 


\section{Conclusions}

Although the focus of this review is on phospholipids, it is important to add that cholesterol and fatty acid changes were also observed in $\mathrm{AD}$ brains and connected with $\mathrm{AD}$ development. These findings were extensively reviewed elsewhere [67-69]. Phospholipids provide an optimal membrane environment for protein interactions, trafficking and function. There is increasing evidence that phospholipid changes occur during pathogenic processes in Alzheimer's disease. Although so far reported CSF/blood phospholipid changes are not specific and sensitive enough to be a diagnostic biomarker, a combination of different sphingolipid CSF and/or blood levels could potentially contribute to more precise AD diagnosis in a very early stage. However, further research is required in order to clearly state that any of those lipids could be used as a biomarker.

\section{Conflict of Interest}

The authors declare no conflict of interest.

\section{References}

1. Veloso, A.; Fernandez, R.; Astigarraga, E.; Barreda-Gomez, G.; Manuel, I.; Giralt, M.T.; Ferrer, I.; Ochoa, B.; Rodriguez-Puertas, R.; Fernandez, J.A. Distribution of Lipids in Human Brain. Anal. Bioanal. Chem. 2011, 401, 89-101.

2. Farooqui, A.A.; Liss, L.; Horrocks, L.A. Neurochemical Aspects of Alzheimers-Disease: Involvement of Membrane Phospholipids. Metab. Brain Dis. 1988, 3, 19-35.

3. Soderberg, M.; Edlund, C.; Kristensson, K.; Dallner, G. Lipid Compositions of Different Regions of the Human-Brain During Aging. J. Neurochem. 1990, 54, 415-423.

4. Svennerholm, L.; Bostrom, K.; Jungbjer, B.; Olsson, L. Membrane-Lipids of Adult Human Brain: Lipid-Composition of Frontal and Temporal-Lobe in Subjects of Age 20 to 100 Years. J. Neurochem. 1994, 63, 1802-1811.

5. Svennerholm, L.; Bostrom, K.; Helander, C.G.; Jungbjer, B. Membrane-Lipids in the Aging Human Brain. J. Neurochem. 1991, 56, 2051-2059.

6. Horrocks, L.A.; VanRollins, M.; Yates, A.J. Lipid Changes in the Ageing Brain. In The Molecular Basis of Neuropathology; Davison, A.N., Thompson, R.H.S., Eds.; Edward Arnold: London, UK, 1981.

7. Ledesma, M.D.; Martin, M.G.; Dotti, C.G. Lipid Changes in the Aged Brain: Effect on Synaptic Function and Neuronal Survival. Prog. Lipid Res. 2012, 51, 23-35.

8. Hirtz, D.; Thurman, D.J.; Gwinn-Hardy, K.; Mohamed, M.; Chaudhuri, A.R.; Zalutsky, R. How Common Are the "Common" Neurologic Disorders? Neurology 2007, 68, 326-337.

9. Ferri, C.P.; Prince, M.; Brayne, C.; Brodaty, H.; Fratiglioni, L.; Ganguli, M.; Hall, K.; Hasegawa, K.; Hendrie, H.; Huang, Y.Q.; et al. Global Prevalence of Dementia: A Delphi Consensus Study. Lancet 2005, 366, 2112-2117.

10. Wenk, G.L. Neuropathologic Changes in Alzheimer's Disease. J. Clin. Psychiatry 2003, 64, 7-10.

11. Querfurth, H.W.; LaFerla, F.M. Mechanisms of Disease Alzheimer's Disease. N. Eng. J. Med. 2010, 362, 329-344. 
12. Blennow, K.; de Leon, M.J.; Zetterberg, H. Alzheimer's Disease. Lancet 2006, 368, 387-403.

13. Blennow, K.; Hampel, H.; Weiner, M.; Zetterberg, H. Cerebrospinal Fluid and Plasma Biomarkers in Alzheimer Disease. Nat. Rev. Neurol. 2010, 6, 131-144.

14. Prasad, M.R.; Lovell, M.A.; Yatin, M.; Dhillon, H.; Markesbery, W.R. Regional Membrane Phospholipid Alterations in Alzheimer's Disease. Neurochem. Res. 1998, 23, 81-88.

15. Stokes, C.E.; Hawthorne, J.N. Reduced Phosphoinositide Concentrations in Anterior Temporal Cortex of Alzheimer-Diseased Brains. J. Neurochem. 1987, 48, 1018-1021.

16. Nitsch, R.M.; Blusztajn, J.K.; Pittas, A.G.; Slack, B.E.; Growdon, J.H.; Wurtman, R.J. Evidence for A Membrane Defect in Alzheimer-Disease Brain. Proc. Natl. Acad. Sci. USA 1992, 89, 1671-1675.

17. Wells, K.; Farooqui, A.A.; Liss, L.; Horrocks, L.A. Neural Membrane Phospholipids in Alzheimer Disease. Neurochem. Res. 1995, 20, 1329-1333.

18. Ginsberg, L.; Rafique, S.; Xuereb, J.H.; Rapoport, S.I.; Gershfeld, N.L. Disease and Anatomic Specificity of Ethanolamine Plasmalogen Deficiency in Alzheimers-Disease Brain. Brain Res. 1995, 698, 223-226.

19. Guan, Z.Z.; Wang, Y.A.; Cairns, N.J.; Lantos, P.L.; Dallner, G.; Sindelar, P.J. Decrease and Structural Modifications of Phosphatidylethanolamine Plasmalogen in the Brain With Alzheimer Disease. J. Neuropathol. Exp. Neurol. 1999, 58, 740-747.

20. Igarashi, M.; Ma, K.Z.; Gao, F.; Kim, H.W.; Rapoport, S.I.; Rao, J.S. Disturbed Choline Plasmalogen and Phospholipid Fatty Acid Concentrations in Alzheimer's Disease Prefrontal Cortex. J. Alzheimers Dis. 2011, 24, 507-517.

21. Pettegrew, J.W.; Panchalingam, K.; Hamilton, R.L.; McClure, R.J. Brain Membrane Phospholipid Alterations in Alzheimer's Disease. Neurochem. Res. 2001, 26, 771-782.

22. Han, X.L.; Holtzman, D.M.; Mckeel, D.W. Plasmalogen Deficiency in Early Alzheimer's Disease Subjects and in Animal Models: Molecular Characterization Using Electrospray Ionization Mass Spectrometry. J. Neurochem. 2001, 77, 1168-1180.

23. Han, X.; Holtzman, M.; McKeel, D.W., Jr.; Kelley, J.; Morris, J.C. Substantial Sulfatide Deficiency and Ceramide Elevation in Very Early Alzheimer's Disease: Potential Role in Disease Pathogenesis. J. Neurochem. 2002, 82, 809-818.

24. He, X.; Huang, Y.; Li, B.; Gong, C.X.; Schuchman, E.H. Deregulation of Sphingolipid Metabolism in Alzheimer's Disease. Neurobiol. Aging 2010, 31, 398-408.

25. Cutler, R.G.; Kelly, J.; Storie, K.; Pedersen, W.A.; Tammara, A.; Hatanpaa, K.; Troncoso, J.C.; Mattson, M.P. Involvement of Oxidative Stress-Induced Abnormalities in Ceramide and Cholesterol Metabolism in Brain Aging and Alzheimer's Disease. Proc. Natl. Acad. Sci. USA 2004, 101, 2070-2075.

26. Bandaru, V.V.; Troncoso, J.; Wheeler, D.; Pletnikova, O.; Wang, J.; Conant, K.; Haughey, N.J. ApoE4 Disrupts Sterol and Sphingolipid Metabolism in Alzheimer's, but Not Normal Brain. Neurobiol. Aging 2009, 30, 591-599.

27. Han, X.L. Potential Mechanisms Contributing to Sulfatide Depletion at the Earliest Clinically Recognizable Stage of Alzheimer's Disease: A Tale of Shotgun Lipidomics. J. Neurochem. 2007, $103,171-179$. 
28. Haughey, N.J.; Bandaru, V.V.R.; Bae, M.; Mattson, M.P. Roles for Dysfunctional Sphingolipid Metabolism in Alzheimer's Disease Neuropathogenesis. Biochim. Biophys. Acta Mol. Cell Biol. Lipids 2010, 1801, 878-886.

29. Van Echten-Deckert, G.; Walter, J. Sphingolipids: Critical Players in Alzheimer's Disease. Prog. Lipid Res. 2012, 51, 378-393.

30. Mulder, C.; Wahlund, L.O.; Teerlink, T.; Blomberg, M.; Veerhuis, R.; van Kamp, G.J.; Scheltens, P.; Scheffer, P.G. Decreased Lysophosphatidylcholine/Phosphatidylcholine Ratio in Cerebrospinal Fluid in Alzheimer's Disease. J. Neural Transm. 2003, 110, 949-955.

31. Walter, A.; Korth, U.; Hilgert, M.; Hartmann, J.; Weichel, O.; Hilgert, M.; Fassbender, K.; Schmitt, A.; Klein, J. Glycerophosphocholine Is Elevated in Cerebrospinal Fluid of Alzheimer Patients. Neurobiol. Aging 2004, 25, 1299-1303.

32. Satoi, H.; Tomimoto, H.; Ohtani, R.; Kitano, T.; Kondo, T.; Watanabe, M.; Oka, N.; Akiguchi, I.; Furuya, S.; Hirabayashi, Y.; et al. Astroglial Expression of Ceramide in Alzheimer's Disease Brains: a Role During Neuronal Apoptosis. Neuroscience 2005, 130, 657-666.

33. Han, X.; Fagan, A.M.; Cheng, H.; Morris, J.C.; Xiong, C.; Holtzman, D.M. Cerebrospinal Fluid Sulfatide Is Decreased in Subjects With Incipient Dementia. Ann. Neurol. 2003, 54, 115-119.

34. Kosicek, M.; Kirsch, S.; Bene, R.; Trkanjec, Z.; Titlic, M.; Bindila, L.; Peter-Katalinic, J.; Hecimovic, S. Nano-HPLC-MS Analysis of Phospholipids in Cerebrospinal Fluid of Alzheimer's Disease Patients-A Pilot Study. Anal. Bioanal. Chem. 2010, 398, 2929-2937.

35. Kosicek, M.; Zetterberg, H.; Andreasen, N.; Peter-Katalinic, J.; Hecimovic, S. Elevated Cerebrospinal Fluid Sphingomyelin Levels in Prodromal Alzheimer's Disease. Neurosci. Lett. 2012, 516, 302-305.

36. Mielke, M.M.; Bandaru, V.V.; Haughey, N.J.; Rabins, P.V.; Lyketsos, C.G.; Carlson, M.C. Serum Sphingomyelins and Ceramides Are Early Predictors of Memory Impairment. Neurobiol. Aging 2010, 31, 17-24.

37. Mielke, M.M.; Haughey, N.J.; Bandaru, V.V.R.; Schech, S.; Carrick, R.; Carlson, M.C.; Mori, S.; Miller, M.I.; Ceritoglu, C.; Brown, T.; et al. Plasma Ceramides Are Altered in Mild Cognitive Impairment and Predict Cognitive Decline and Hippocampal Volume Loss. Alzheimer's Dementia 2010, 6, 378-385.

38. Mielke, M.M.; Lyketsos, C.G. Alterations of the Sphingolipid Pathway in Alzheimer's Disease: New Biomarkers and Treatment Targets? Neuromol. Med. 2010, 12, 331-340.

39. Mattsson, N.; Zetterberg, H.; Hansson, O.; Andreasen, N.; Parnetti, L.; Jonsson, M.; Herukka, S.K.; van der Flier, W.M.; Blankenstein, M.A.; Ewers, M.; et al. CSF Biomarkers and Incipient Alzheimer Disease in Patients With Mild Cognitive Impairment. J. Am. Med. Assoc. 2009, 302, 385-393.

40. Cheng, H.; Xu, J.; Mckeel, D.W.; Han, X. Specificity and Potential Mechanism of Sulfatide Deficiency in Alzheimer's Disease: An Electrospray Ionization Mass Spectrometric Study. Cell. Mol. Biol. 2003, 49, 809-818.

41. Fredman, P.; Wallin, A.; Blennow, K.; Davidsson, P.; Gottfries, C.G.; Svennerholm, L. Sulfatide As A Biochemical Marker in Cerebrospinal Fluid of Patients With Vascular Dementia. Acta Neurol. Scand. 1992, 85, 103-106. 
42. Jonsson, M.; Zetterberg, H.; Rolstad, S.; Edman, A.; Gouw, A.A.; Bjerke, M.; Lind, K.; Blennow, K.; Pantoni, L.; Inzitari, D.; et al. Low Cerebrospinal Fluid Sulfatide Predicts Progression of White Matter Lesions-The LADIS Study. Dementia Geriatr. Cognit. Disord. 2012, 34, 61-67.

43. Han, X. Lipid Alterations in the Earliest Clinically Recognizable Stage of Alzheimer's Disease: Implication of the Role of Lipids in the Pathogenesis of Alzheimer's Disease. Curr. Alzheimer Res. 2005, 2, 65-77.

44. Strittmatter, W.J.; Roses, A.D. Apolipoprotein E and Alzheimer's Disease. Ann. Rev. Neurosci. 1996, 19, 53-77.

45. Verghese, P.B.; Castellano, J.M.; Holtzman, D.M. Apolipoprotein E in Alzheimer's Disease and Other Neurological Disorders. Lancet Neurol. 2011, 10, 241-252.

46. Keene, C.D.; Cudaback, E.; Li, X.W.; Montine, K.S.; Montine, T.J. Apolipoprotein E Isoforms and Regulation of the Innate Immune Response in Brain of Patients with Alzheimer's Disease. Curr. Opin. Neurobiol. 2011, 21, 920-928.

47. Han, X.L.; Cheng, H.; Fryer, J.D.; Fagan, A.M.; Holtzman, D.M. Novel Role for Apolipoprotein E in the Central Nervous System-Modulation of Sulfatide Content. J. Biol. Chem. 2003, 278, 8043-8051.

48. Han, X.L. Multi-Dimensional Mass Spectrometry-Based Shotgun Lipidomics and the Altered Lipids at the Mild Cognitive Impairment Stage of Alzheimer's Disease. Biochim. Biophys. Acta Mol. Cell Biol. Lipids 2010, 1801, 774-783.

49. Bartke, N.; Hannun, Y.A. Bioactive Sphingolipids: Metabolism and Function. J. Lipid Res. 2009, 50, S91-S96.

50. Colombaioni, L.; Garcia-Gil, M. Sphingolipid Metabolites in Neural Signalling and Function. Brain Res. Rev. 2004, 46, 328-355.

51. Katsel, P.; Li, C.; Haroutunian, V. Gene Expression Alterations in the Sphingolipid Metabolism Pathways During Progression of Dementia and Alzheimer's Disease: A Shift Toward Ceramide Accumulation at the Earliest Recognizable Stages of Alzheimer's Disease? Neurochem. Res. 2007, 32, 845-856.

52. Lee, J.T.; Xu, J.; Lee, J.M.; Ku, G.; Han, X.L.; Yang, D.I.; Chen, S.W.; Hsu, C.Y. Amyloid-Beta Peptide Induces Oligodendrocyte Death by Activating the Neutral Sphingomyelinase-Ceramide Pathway. J. Cell Biol. 2004, 164, 123-131.

53. Patil, S.; Melrose, J.; Chan, C. Involvement of Astroglial Ceramide in Palmitic Acid-Induced Alzheimer-Like Changes in Primary Neurons. Eur. J. Neurosci. 2007, 26, 2131-2141.

54. Puglielli, L.; Ellis, B.C.; Saunders, A.J.; Kovacs, D.M. Ceramide Stabilizes Beta-Site Amyloid Precursor Protein-Cleaving Enzyme 1 and Promotes Amyloid Beta-Peptide Biogenesis. J. Biol. Chem. 2003, 278, 19777-19783.

55. Horres, C.R.; Hannun, Y.A. The Roles of Neutral Sphingomyelinases in Neurological Pathologies. Neurochem. Res. 2012, 37, 1137-1149.

56. Pike, L.J. The Challenge of Lipid Rafts. J. Lipid Res. 2009, 50, S323-S328.

57. Pike, L.J. Lipid Rafts: Heterogeneity on the High Seas. Biochem. J. 2004, 378, 281-292.

58. Ehehalt, R.; Keller, P.; Haass, C.; Thiele, C.; Simons, K. Amyloidogenic Processing of the Alzheimer Beta-Amyloid Precursor Protein Depends on Lipid Rafts. J. Cell Biol. 2003, 160, 113-123. 
59. Riddell, D.R.; Christie, G.; Hussain, I.; Dingwall, C. Compartmentalization of Beta-Secretase (Asp2) into Low-Buoyant Density, Noncaveolar Lipid Rafts. Curr. Biol. 2001, 11, 1288-1293.

60. Vetrivel, K.S.; Cheng, H.P.; Lin, W.; Sakurai, T.; Li, T.; Nukina, N.; Wong, P.C.; Xu, H.X.; Thinakaran, G. Association of Gamma-Secretase With Lipid Rafts in Post-Golgi and Endosome Membranes. J. Biol. Chem. 2004, 279, 44945-44954.

61. Wahrle, S.; Das, P.; Nyborg, A.C.; McLendon, C.; Shoji, M.; Kawarabayashi, T.; Younkin, L.H.; Younkin, S.G.; Golde, T.E. Cholesterol-Dependent Gamma-Secretase Activity in Buoyant Cholesterol-Rich Membrane Microdomains. Neurobiol. Dis. 2002, 9, 11-23.

62. Kosicek, M.; Malnar, M.; Goate, A.; Hecimovic, S. Cholesterol Accumulation in Niemann Pick Type C (NPC) Model Cells Causes a Shift in APP Localization to Lipid Rafts. Biochem. Biophys. Res. Commun. 2010, 393, 404-409.

63. Cordy, J.M.; Hussain, I.; Dingwall, C.; Hooper, N.M.; Turner, A.J. Exclusively Targeting Beta-Secretase to Lipid Rafts by GPI-Anchor Addition Up-Regulates Beta-Site Processing of the Amyloid Precursor Protein. Proc. Natl. Acad. Sci. USA 2003, 100, 11735-11740.

64. Vetrivel, K.S.; Meckler, X.; Chen, Y.; Nguyen, P.D.; Seidah, N.G.; Vassar, R.; Wong, P.C.; Fukata, M.; Kounnas, M.Z.; Thinakaran, G. Alzheimer Disease A Beta Production in the Absence of S-Palmitoylation-Dependent Targeting of BACE1 to Lipid Rafts. J. Biol. Chem. 2009, 284, 3793-3803.

65. Cheng, H.P.; Vetrivel, K.S.; Drisdel, R.C.; Meckler, X.; Gong, P.; Leem, J.Y.; Li, T.; Carter, M.; Chen, Y.; Nguyen, P.; et al. S-Palmitoylation of Gamma-Secretase Subunits Nicastrin and APH-1. J. Biol. Chem. 2009, 284, 1373-1384.

66. Rajendran, L.; Schneider, A.; Schlechtingen, G.; Weidlich, S.; Ries, J.; Braxmeier, T.; Schwille, P.; Schulz, J.B.; Schroeder, C.; Simons, M.; et al. Efficient Inhibition of the Alzheimer's Disease Beta-Secretase by Membrane Targeting. Science 2008, 320, 520-523.

67. Hartmann, T.; Kuchenbecker, J.; Grimm, M.O. Alzheimer's Disease: The Lipid Connection. J. Neurochem. 2007, 103, 159-170.

68. Martins, I.J.; Berger, T.; Sharman, M.J.; Verdile, G.; Fuller, S.J.; Martins, R.N. Cholesterol Metabolism and Transport in the Pathogenesis of Alzheimer's Disease. J. Neurochem. 2009, 111, 1275-1308.

69. Stefani, M.; Liguri, G. Cholesterol in Alzheimer's Disease: Unresolved Questions. Curr. Alzheimer Res. 2009, 6, 15-29.

(C) 2013 by the authors; licensee MDPI, Basel, Switzerland. This article is an open access article distributed under the terms and conditions of the Creative Commons Attribution license (http://creativecommons.org/licenses/by/3.0/). 